\title{
Burden of non-communicable diseases in Iraq after the 2003 war
}

\author{
Ashraf M. Hussain, MD, PhD, Riyadh K. Lafta, MD, PhD.
}

$$
\begin{aligned}
& \text { ABSTRACT }
\end{aligned}
$$

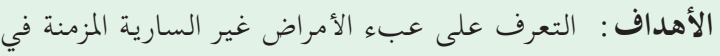

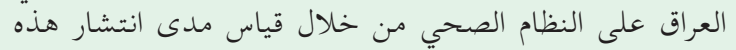

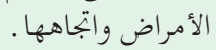

$$
\begin{aligned}
& \text { الطريقة : أجريت هذه الدراسة الوصفية خلال الفترة من يناير }
\end{aligned}
$$

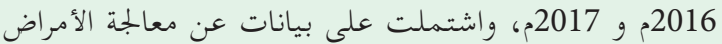

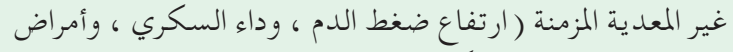

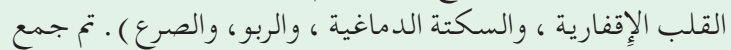

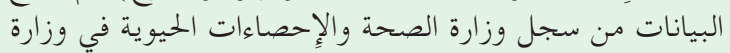

$$
\begin{aligned}
& \text { الصحة، بابل، العراق، بين عامي 2000م و 2016م. لإحصاء الصيو } \\
& \text { النتائج: ارتفع معدل انتشار داء السكري بشكل ملحوظ في فام }
\end{aligned}
$$

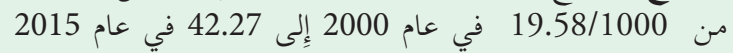

$$
\begin{aligned}
& \text { (31.33 } \\
& 31.33 \text { إلى } 45.82 \text { ( } 450.0002 \text { ( }
\end{aligned}
$$

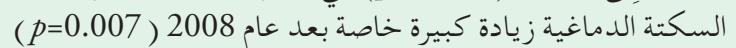

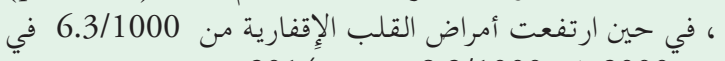

$$
\begin{aligned}
& \text { عام } 2000 \text { إِلى إنى } \\
& \text { إِحصائي كبير }
\end{aligned}
$$

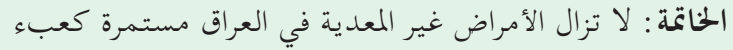

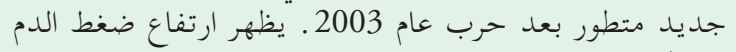

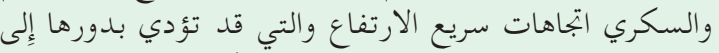

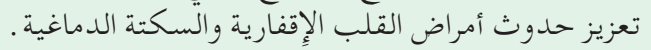

Objectives: To figure out the burden of chronic noncommunicable diseases in Iraq on the health system through measuring the incidence and trend of these diseases.

Methods: This descriptive study that was conducted between January 2016 and 2017, involved treatment data of chronic non-communicable diseases (hypertension, diabetes mellitus, ischemic heart disease, stroke, asthma and epilepsy). The data was collected from the registry of the Department of Health and Vital Statistics in the Ministry of Health, Babylon, Iraq, between 2000 and 2016.
Results: The prevalence of diabetes mellitus had significantly increased from $19.58 / 1000$ in the year 2000 to 42.27 in $2015(p=0.0002)$. The prevalence of hypertension also increased from 31.33 to 45.82 $(p=0.003)$ in the same period. The prevalence of cerebrovascular accidents showed a significant increase especially after $2008(p=0.007)$, while ischemic heart diseases increased from 6.3/1000 in the year 2000 to $8.2 / 1000$ in 2014 with no significant change.

Conclusion: Non-communicable diseases in Iraq continue to show as a new developing burden after the 2003 war. Hypertension and diabetes mellitus demonstrate rapidly rising trends which may, in turn, enhance the occurrence of ischemic heart diseases and cerebrovascular accidents.

Saudi Med J 2019; Vol. 40 (1): 72-78 doi: 10.15537/smj.2019.1.23463

From the Department of Family and Community Medicine (Hussain), College of Medicine, University of Babylon, Babylon, Iraq, and from the Department of Family and Community Medicine (Lafta), College of Medicine, Mustansiriya University, Global Health Department, University of Washington, Seattle, United States of America.

Received 18th August 2018. Accepted 5th December 2018

Address correspondence and reprint request to: Dr. Ashraf $M$. Hussain, Department of Family and Community Medicine, College of Medicine, University of Babylon, Babylon, Iraq. E-mail: ashrafhussain1981@yahoo.com

ORCID ID: orcid.org/0000-0003-2916-8205

E pidemiological transition in industrialized countries started around 1900, with increase of the chronic and degenerative diseases that peaked around 1950 accompanied by marked fall in infectious diseases mortality and morbidity. ${ }^{1}$ This was not shared equally by all nations of the globe; in the developing countries, the prevalence of old, emerging and re-emerging communicable diseases have been constant or increasingly occurring. ${ }^{2}$ The burden of non-communicable diseases defines the national health 
challenges that constrain the economic and social progress all over the world. ${ }^{3}$ This group of diseases causes 40 million deaths annually, approximately one third of these are premature deaths mostly in the low and middle income countries (80\%), furthermore these diseases have a ingrained effect on disability trends, in which they are estimated to be responsible for approximately two third of years lived with disability in those countries. ${ }^{4-6}$ The burden categorization of a disease can range from the incidence and prevalence to its effect on the longevity, morbidity, state of health, quality of life and the monetary aspects that include direct and indirect loss arising from premature death, disability or injury due to the disease or its complications. ${ }^{7}$

Since 2010, the Eastern Mediterranean region (EMR) entered in a whirl of unrest. ${ }^{8}$ War and other armed conflicts usually result in severe morbidity and mortality. Many social and health problems occurred during and following the conflicts manifested by destruction of the health system infrastructures, lack of food and safe water, poor sanitation, lack of medical care and health services. ${ }^{9}$ The global burden of disease (GBD) 2015 study showed that the leading cause of death in the EMR last years was ischemic heart diseases with a rate of $90.3 / 100000$, which rose by $17.2 \%$ since 1990 , while high blood pressure increased by $83.3 \%$ since 1990. ${ }^{4}$ The first gulf war in 1991 caused vast destruction to the Iraqi major infrastructures essential for healthy life. ${ }^{10}$ The economic sanction came to aggravate the condition of deterioration with health care budget almost cut by $90 \% .{ }^{11}$ Approximately $12 \%$ of the hospitals were damaged during the United States of America (US) invasion or thereafter. ${ }^{12}$ Understaffed and weakly resourced hospitals have struggled to overcome the raised load of sick and injured attendants and to provide them with the required essential care. ${ }^{13}$

Rationale of the study. The duple burden of diseases (old and new) makes it difficult for policy makers to address the variable population health needs. The current study was a trial to portray the trend of chronic non-communicable diseases in the form of incidence and prevalence, in order to assess the burden of these disease over around a decade and a half to highlight the problems that are facing our health system.

Methods. This descriptive study that was conducted during the period between January 2016 and 2017,

Disclosure. Authors have no conflict of interests, and the work was not supported or funded by any drug company. involved treatment and processing of data related to chronic non-communicable diseases.

The data encompass the most prevalent chronic health problems including hypertension, diabetes mellitus, ischemic heart disease, stroke, asthma and epilepsy. Data was collected from the registry of the specialized Department of Health and Vital Statistics in the Ministry of Health, and supported by data from the Division of Non-Communicable Diseases Control and Prevention Center and some survey data. Data was formed from hospital discharge registries and outpatient visits to the hospitals and primary health care centers. All registries of non-communicable diseases during the period from 2000-2016 were included; however, incomplete registries were excluded to enhance accuracy.

The total sample was $40,927,512$, of which, $12,025,843$ were diabetes mellitus, 14,516,532 hypertension, 2,823,290 ischemic heart diseases, 570,021 cerebrovascular accident, 10,107,239 were asthma and 884,587 were cases of epilepsy.

Data was gathered on monthly basis, triple checked and confirmed by data from other official sources to fill the gaps caused by missing data and to increase reliability.

To measure the rate of occurrence; the total population for each governorate, and for Iraq, was obtained from the central statistical organization to be used as denominators; these rates were then plotted against time to define the trend.

In respect with age, data was categorized into: under 15 years, $15-45$ years, and more than 45 years in accordance with the original categorization of noncommunicable diseases (NCD) center of the Ministry of Health. The number of cases of the 3 age groups also plotted against time to get the trend of each disease by age and to detect changes in age of predilection.

Ethical approvals were granted by the Ethical Committee in the College of Medicine, Mustansiriyah University and the Iraqi Ministry of Health in Iraq. As this is a surveillance study that deals only with numbers, and with no intervention, so indication according to the principles of Helsinki Declaration was not applicable.

The Statistical Package for Social Sciences (SPSS) Version 23 (IBM Corp., Armonk, NY, USA) was used to estimate the rates. Linear regression was calculated to estimate the trends of the disease. The outcome depended on the picture of the slop whether going downward, upward, flat, or unpredictable, to assess the trend. A $p=0.05$ was considered significant. 
The percentage change was calculated for the whole and mid time periods as a measure of difference in the trend for each disease, using the following formula:

$$
\mathrm{PC}=\frac{\mathrm{R} 2-\mathrm{R} 1}{\mathrm{R} 1}
$$

Where as: PC stands for percent change, $\mathrm{R} 2$ stands for new rate, and R1 for old rate.

Results. Diabetes mellitus. The prevalence of diabetes mellitus had significantly raised from $19.58 / 1000$ in the year 2000 to $42.27 / 1000$ in 2016 with a percent change of $38.25(p=0.0002)$. Males and females were affected almost equally. The majority of cases aged more than 45 years are shown in Figure 1, never the less, there was a small proportion $(5 \%)$ aged less than 15 years.

Hypertension. The prevalence of hypertension in Iraq showed a significant change during the last 17 years from $31.33 / 1000$ in the year 2000 to $45.82 / 1000$ in 2015 ( $p=0.003)$, mostly among adults more than 45 years (Figure 2 ). Both genders were almost equally affected.

Ischemic heart disease. The trend of ischemic heart diseases increased from 6.3/1000 in the year 2000 to $8.2 / 1000$ in 2014; however, this increase in the trend could not reach a significant level. Both genders were affected almost equally and mostly after the age of 45 years (Figure 3).

Cerebrovascular accidents. The prevalence of cerebrovascular accidents (CVA) in Iraq showed a significant increase especially after 2008 with a percent change of $56.91(p=0.007)$. Both genders were similarly affected, mostly above the age of 45 years (Figure 4).

Asthma. The occurrence of asthma showed no significant changes in its trend (Figure 5). Both genders were almost equally affected, more than $40 \%$ of the cases aged less than 15 years, and $40 \%$ aged 45 years or more.

Epilepsy. The trend of epilepsy had a step rise in its occurrence as shown in Figure 6. It had been raised since 2008, affected both genders with a similar rate, the number of cases was more in the age group more than 45 years.

Table 1 shows the percent change in incidence rate of chronic non-communicable diseases for the period 2000-2016.

Discussion. Non-communicable diseases are responsible for 2 of every 3 years lived with disability. ${ }^{14}$ The burden of chronic non-communicable diseases is

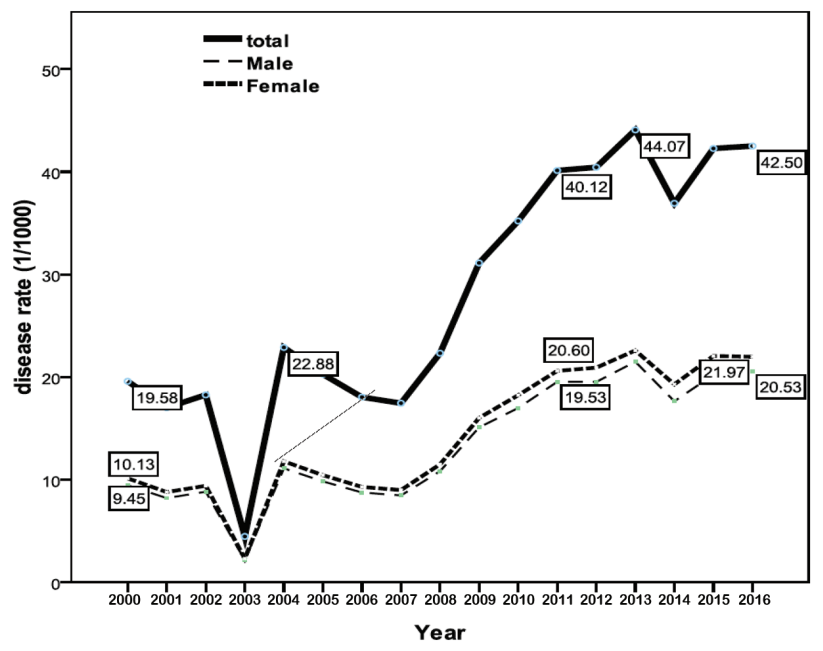

Figure 1 - Trend of diabetes mellitus distributed by gender (2000-2016), $p=0.0002$.

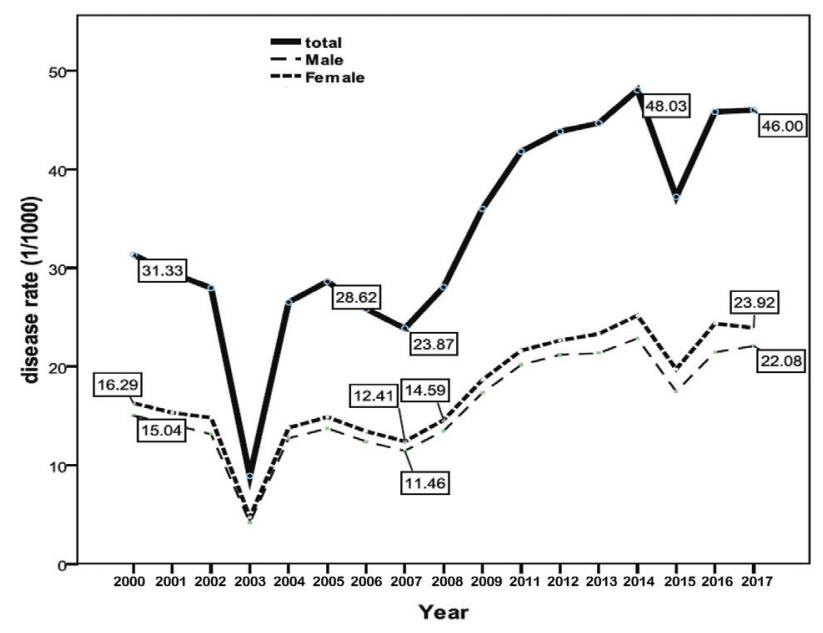

Figure 2 - Trend of hypertension distributed by gender (2000-2016), $p=0.003$.

immense as it forms $75 \%$ of the global mortality ${ }^{15}$ and $75 \%$ of the global GDP (approximately 63 trillion US dollars), or per capita cost of approximately 139 US dollars. ${ }^{16}$ As the portrayed trend in the current study represents the rate of patients attending the health facilities rather than the real prevalence, so this may only reflect the utilization of such services giving an obvious unavoidable underestimation.

Our findings revealed that diabetes mellitus increased significantly from $19.5 / 1000$ in the year 2000 up to $42.1 / 1000$ in 2015 with a percent change of $115 \%$. World Health Organization (WHO) reported a collateral raised age standardized prevalence rate of 


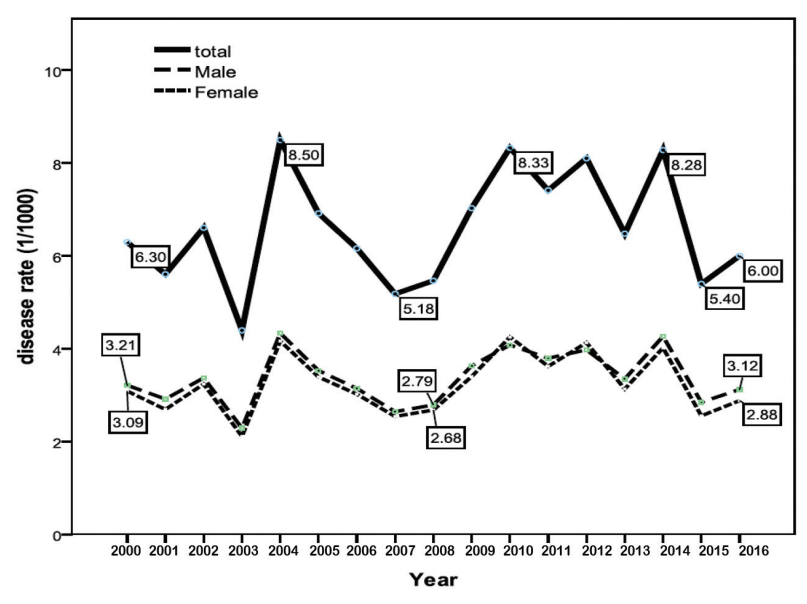

Figure 3 - Ischemic heart diseases by gender (2000-2016), $p=0.814$.

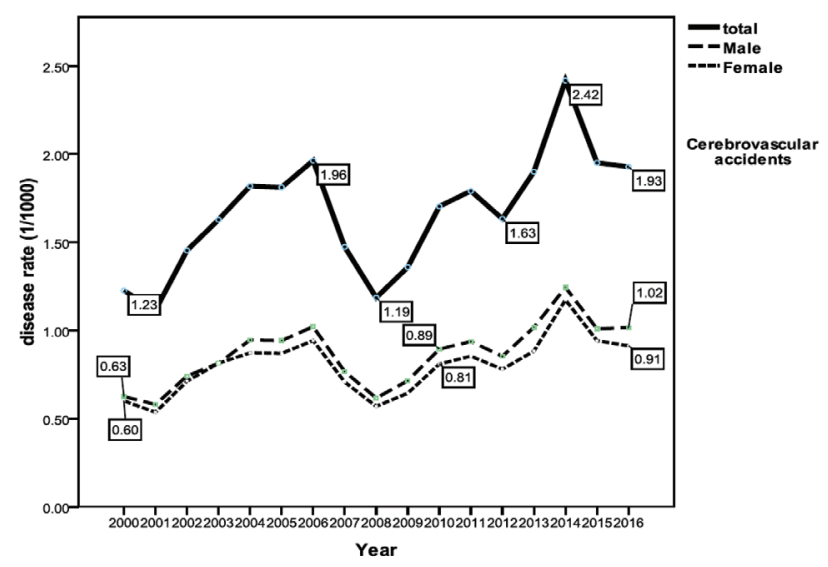

Figure 4 - Cerebro-vascular accidents by gender (2000-2016), $p=0.007$.

diabetes among Iraqi populations from 12.5-17.5\% during 2000-2014. ${ }^{17}$ This trend goes with what is happening in the regional countries such as Kingdom of Saudi Arabia, Lebanon and Iran and the whole world. ${ }^{18-21}$ The number of diabetic almost quadrupled since the year 1980, it is estimated that the number in 2015 reached 422 million 22 with a prevalence rate of $8.8 \%$ or one of every 11 persons. ${ }^{23}$ This ascending prevalence is more in the middle and low income countries and mirrors the high prevalence of overweight and obesity and the widespread lack of physical activity. ${ }^{24}$ Diabetes is the 6th leading cause of disability and the third global risk factor following hypertension and smoking. ${ }^{25}$ The burden of diabetes comes from its expenditure that accounts $12 \%$ of the total health expenditure reaching 673 billion US dollars according to the International Diabetes Federation (IDF) estimation. A study in Singapore estimated the total financial burden from

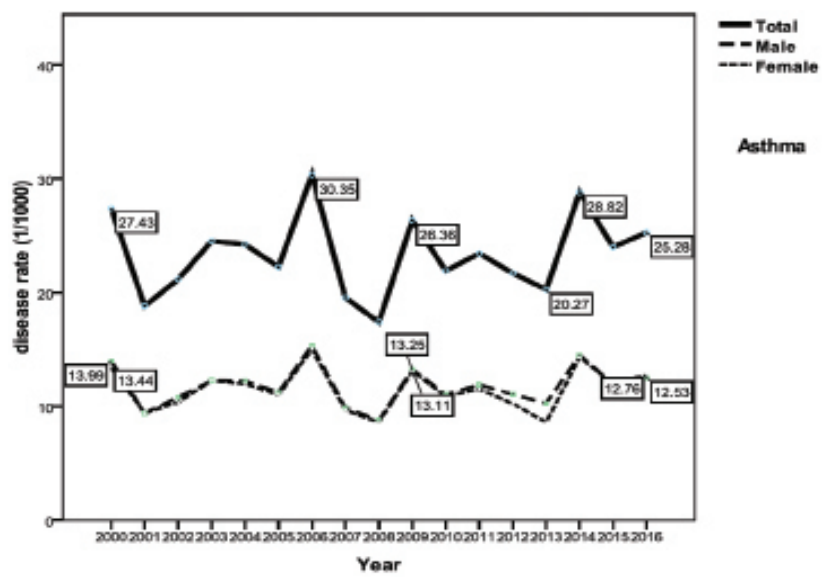

Figure 5 - Trend of asthma by gender (2000-2016), $p=0.285$.

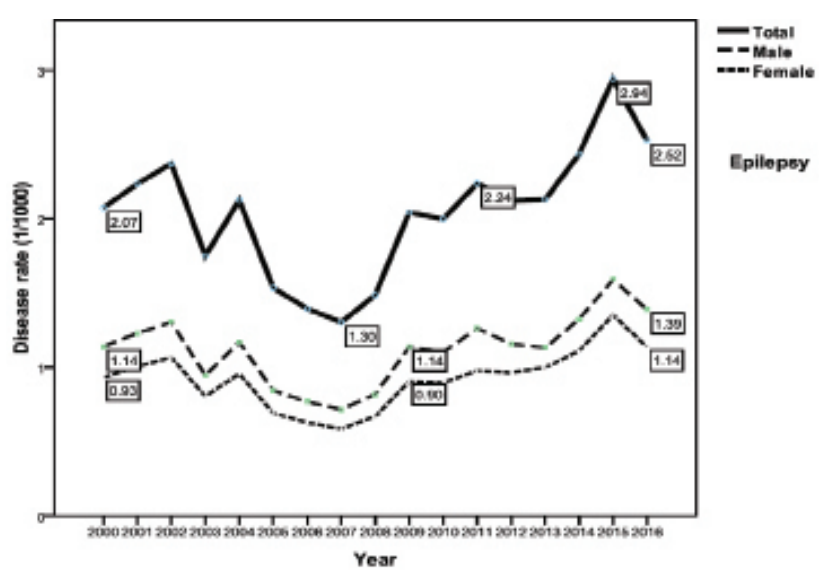

Figure 6 - Trend of epilepsy by gender (2000-2016), $p=0.09$.

type 2 diabetes at approximately 5000 US dollars per patient. ${ }^{26}$ This is superadded by the wide range of serious complications such as ischemic heart disease, nephropathy, retinopathy and amputations that disturb the patients' life. ${ }^{27}$ Diabetes is a leading cause of death, where in 2012 it caused the death of 1.5 million people directly and 2.2 million through an increased risk of cardiovascular and other diseases. Forty three percent of these deaths occur at the productive age before 70 years and is higher in middle and low income countries. The estimated prevalence of diabetes/hyperglycemia in Iraq according to $\mathrm{WHO}$ country profile is $13.2 \%$, and three fourth of them are on Insulin. ${ }^{17,21}$ Hypertension also showed a progressively raising rate from $31.33 / 1000$ in 2000 to $45.8 / 1000$ in 2015 with a drop in 2003 that was associated with the USA invasion of Iraq and the disrupted health surveillance system at that year. According to STEPwise approach to Surveillance 
Table 1 - Percent change in prevalence rate (1/1000) of studied non communicable diseases (2000-2016).

\begin{tabular}{lcccccc}
\hline Disease & Rate 2000 & Rate 2008 & Percent change 2000-2008 & Rate 2016 & Percent change 2008-2016 & Percent change 2000-2016 \\
\hline Diabetes mellitus & 19.58 & 22.32 & 13.99 & 27.07 & 21.28 & 38.25 \\
Hypertension & 31.33 & 28.05 & -10.47 & 30.24 & 7.81 & -3.48 \\
Ischemic heart disease & 6.30 & 5.50 & -12.70 & 4.01 & -27.09 & -36.35 \\
Cerebro-vascular accidents & 1.23 & 1.19 & -3.25 & 1.93 & 62.18 & 56.91 \\
Asthma & 27.43 & 17.40 & -36.57 & 25.28 & 45.29 & -7.84 \\
Epilepsy & 2.07 & 1.49 & -28.02 & 2.52 & 69.13 & 21.74 \\
\hline
\end{tabular}

(STEPS) surveys; the prevalence of hypertension declined from $40.4 \%$ in 2006 to $35.5 \%$ in $2015 .^{28}$ Turkey reported a stable rate within $30 \%$ in the period 2003-2012, Iran showed a mild rise between 20072011. ${ }^{29,30}$ Hypertension is thought to be responsible for more than half of the death cases caused by strokes or ischemic heart diseases. ${ }^{31}$ From financial point of view the presence of hypertension was estimated to double the health expenditure of an individual, which is further redoubled by co-presence of diabetes. ${ }^{32}$ The prevalence of hypertension in the Eastern Mediterranean region is near the highest (41\%) with high income countries have lower prevalence of hypertension (35\%) than the low and middle income ones (40\%). ${ }^{33}$ According to STEP survey (2015), the prevalence of hypertension was $35.6 \%$, being higher among men with a very low control rate $(7.9 \%)$. Hypertension formed approximately $19 \%$ of the total disability-adjusted life year (DALY) loss in 2015. It also accounts for 9.4 million deaths worldwide annually, and responsible for at least $45 \%$ of deaths due to heart diseases and $51 \%$ of those due to stroke. ${ }^{34}$ Ischemic heart disease showed a fluctuant trend ranging between 4.5 and 8.5/1000. It witnessed a decrease in its rate in 2015-2016 down to 4.01/1000. Ischemic heart diseases are the main cause of death worldwide and account for $16 \%$ of all death causes in the region. ${ }^{4}$

Globally; there were approximately 17.7 million deaths from cardiovascular diseases in 2015 representing nearly $30 \%$ of the global total deaths, 7.4 million caused by ischemic heart diseases and 6.7 million were due to stroke. ${ }^{35}$ Both occupied the first 2 causes of premature deaths and high years of life lost (YLLs) globally. ${ }^{4}$ This picture differs among different world regions where the last 25 years witnessed a decrease in cardiovascular deaths (mainly coronary diseases) by more than $50 \%$ in high income countries while low and middle income countries showed a flat or even increasing trend. ${ }^{36}$ Even within the developed societies, the lower socioeconomic groups have higher incidence and mortality of cardiovascular diseases due to poorer risk factor profile. ${ }^{37}$ In Iraq, ischemic heart diseases occupied the second cause of premature deaths after war and violent deaths with stroke been the fourth of the main $10 .{ }^{4}$ In the current study, an interesting finding was that although diabetes mellitus showed a significantly increased trend, yet, the prevalence of ischemic heart diseases has not been increased in the same rate, this could be explained by that this spike in the trend of diabetes mellitus in Iraq is recent and so, its effect (as a risk factor) on ischemic heart diseases did not get enough time to appear, probably, the coming years may make this effect more clear. Cerebrovascular accidents almost doubled between 2000-2013 from 1.23-2.42/100000. The most prominent burden of stroke is its high case fatality rate which is approximately $12.7 \%$ globally, while in Iraq; a hospital based study estimated it to be $22.7 \% .^{38}$ Stroke is the third main cause of mortality in Iraq and accounts for $9.3 \%$ of all deaths, survivors often get an associated long term disability. ${ }^{39}$

Asthma remained within the same range of 20-30/1000. The National estimation of the prevalence of asthma in Iraq by Iraq Family Health Survey (IFHS) in 2006 provided a rate of 8.3 per 1000 which is comparable to the rates in the neighboring countries such as Iran, while in 2015 it jumped to 22 per 1000 (2.2\%). ${ }^{40,41,28}$ The prevalence of asthma was more in young people, probably due to the registration method as many of the cases of asthma in adults are included within the category of chronic obstructive lung diseases.

Asthma is one of the major non-communicable diseases affects approximately 240 million people in 2016 worldwide, mostly children. ${ }^{42}$ It affects all countries regardless the level of development but mortality been higher in low and middle income countries reaching approximately $80 \%$ of all Asthma related deaths. ${ }^{43}$

The trend of epilepsy had a mild rise with a percent change of $21 \%$. STEPwise approach to Surveillance Survey 2015 reported a prevalence rate of epilepsy of $0.4 \%$ which was much lower than that of Egypt (5.1/1000) and Kingdom of Saudi Arabia (6.5\%). ${ }^{44}$

Limitations of the study. There is an underestimation for most of the rates of the studied diseases as data was 
collected from the registries of hospitals and primary health care centers and not population based. Many of our patients prefer to attend the private clinics for a better care, those patients are not registered in the statistics of the Ministry of Health as the private sector is not included in the surveillance system.

In conclusion, it can be interpreted from this study that non-communicable diseases in Iraq continue to show as a new developing burden with a raised trend for all. Hypertension and diabetes mellitus demonstrated rapidly rising trends which may, in turn, enhance the occurrence of ischemic heart diseases and CVA.

\section{References}

1. Amuna P, Zotor FB. Epidemiological and nutrition transition in developing countries: impact on human health and development. Proc Nutr Soc 2008; 67: 82-90.

2. Nii-Trebi NI. Emerging and Neglected Infectious Diseases: Insights, Advances, and Challenges. Biomed Res Int 2017; 2017: 5245021.

3. World Health Organization. Global action plan for the prevention and control of noncommunicable diseases 2013-2020 [Internet]. [Accessed 2018 February 27]. Geneva: WHO; 2013 Available from: http://africahealthforum.afro. who.int/IMG/pdf/global_action_plan_for_the_prevention_ and_control_of_ncds_2013-2020.pdf

4. GBD 2015 Mortality and Causes of Death Collaborators. Global, regional, and national life expectancy, all-cause mortality, and cause-specific mortality for 249 causes of death, 1980-2015: a systematic analysis for the Global Burden of Disease Study 2015. The Lancet 2016; 388: 1459-1544.

5. Baldwin W. The Burden of Non-Communicable Diseases in the Developing World [Internet]. [Accessed 2018 March 22]. Available from: https://www.ahrq.gov/professionals/education/ curriculum-tools/population-health/baldwin.html

6. World Health Organization. Noncommunicable Diseases Progress Monitor, 2017. [Accessed 2018 March 25]. Available at: http://apps.who.int/iris/bitstream/ handle/10665/258940/9789241513029-eng.pdf?sequence=1.

7. Jo C. Cost-of-illness studies: concepts, scopes, and methods. Clin Mol Hepatol 2014; 20: 327-337.

8. Henry C, Ji-hyang J. The Arab Spring: will it lead to democratic transitions? [Internet]. [Update 2012, Accessed 2018 April 11]. Available from: http://doi.org/10.1057/9781137344045

9. Lafta R, Al-Shatari S, Cherewick M, Galway L, Mock C, Hagopian A, et al. Injuries, death, and disability associated with 11 years of conflict in Baghdad, Iraq: A randomized household cluster survey. PLoS One 2015; 10: e0131834.

10. Al Hilfi TK, Lafta R, Burnham G. Health services in Iraq. Lancet 2013; 381: 939-948.

11. Cetorelli V, Shabila NP. Expansion of health facilities in Iraq a decade after the US-led invasion, 2003-2012. Confl Health 2014; 8: 16.

12. Rubenstein LS, Bittle MD. Responsibility for protection of medical workers and facilities in armed conflict. Lancet 2010; 375: 329-340.
13. United Nations Office for the Coordination of Humanitarian Affairs. Humanitarian Response Plan-Iraq. [Update 2017, Accessed 2018 April 20]. Available at: https://www. humanitarianresponse.info/system/files/documents/files/2017_ hrp_irq_final.pdf.

14. Richards NC, Gouda HN, Durham J, Rampatige R, Rodney A, Whittaker M. Disability, noncommunicable disease and health information. Bull World Health Organ 2016; 94: 230-232.

15. World Health Organization. Noncommunicable diseases [Internet]. [Updated 2015, Accessed 2018 March 15]. Available from: https:/www.who.int/en/news-room/fact-sheets/detail/ noncommunicable-diseases

16. World Economic Forum. From burden to "Best Buys": reducing the economic impact of non-communicable diseases in low- and middle-income countries. [Accessed 2018 May 1]. Available at: http://apps.who.int/medicinedocs/documents/ s18804en/s18804en.pdf

17. World Health Organization. Diabetes country profiles [Accessed 2016, Accessed 2018 March 30]. Available from: https://www. who.int/diabetes/country-profiles/irq_en.pdf

18. Alotaibi A, Perry L, Gholizadeh L, Al-Ganmi A. Incidence and prevalence rates of diabetes mellitus in Saudi Arabia: An overview. J Epidemiol Glob Health 2017; 7: 211-218.

19. Nakhoul N, Tamim H, Mouneimne Y, Nasreddine L, Abiad $\mathrm{M}$, Ismaeel $\mathrm{H}$, et al. Is the prevalence of diabetes increasing in Lebanon? [Updated 2015, Accessed 2018 April 18]. Available from: http://press.endocrine.org/doi/abs/10.1210/endomeetings.2015.DGM.17.LBS-107

20. Esteghamati A, Etemad K, Koohpayehzadeh J, Abbasi M, Meysamie A, Noshad S, et al. Trends in the prevalence of diabetes and impaired fasting glucose in association with obesity in Iran: 2005-2011. Diabetes Res Clin Pract 2014; 103: 319-327.

21. World Health Organization. Global report on diabetes. [Update 2016; Accessed 2018 March 23]. Available at: https://www. who.int/diabetes/publications/en/

22. World Health Organization. 10 facts on diabetes. [Update 2016; Accessed 2018 April 1]. Available from: https://www. who.int/features/factfiles/diabetes/en/

23. World Health Organization. Diabetes Programme [Update 2018; Accessed 2018 May 01]. Available from: https://www. who.int/diabetes/en/

24. International Diabetes Federation. IDF Diabetes Atlas. 4th ed. [Update 2009; Accessed 2018 April 15]. Available at: file:// Users/Jing/Downloads/IDF-Diabetes-Atlas-4th-edition.pdf

25. GBD 2015 Risk Factors Collaborators. Global, regional, and national comparative risk assessment of 79 behavioural, environmental and occupational, and metabolic risks or clusters of risks, 1990-2015: a systematic analysis for the Global Burden of Disease Study 2015. Lancet 2016; 388: 1659-1724.

26. Png ME, Yoong J, Phan TP, Wee HL. Current and future economic burden of diabetes among working-age adults in Asia: conservative estimates for Singapore from 2010-2050. BMC Public Health 2016; 16: 153.

27. Trikkalinou A, Papazafiropoulou AK, Melidonis A. Type 2 diabetes and quality of life. World J Diabetes 2017; 8: 120-129.

28. World Health Organization. Noncommunicable diseases risk factors STEPS Survey, Iraq 2015. [Update 2015; Accessed 2018 January 31]. Available at: https://www.who.int/ncds/ surveillance/steps/Iraq_2015_STEPS_Report.pdf 
29. Sengul S, Akpolat T, Erdem Y, Derici U, Arici M, Sindel S, et al. Changes in hypertension prevalence, awareness, treatment, and control rates in Turkey from 2003 to 2012. J Hypertens 2016; 34: 1208-1217.

30. World Health Organization. Iran NCD Risk Factors STEPs Report. [Update 2011; Accessed 2018 FebruaryAccessed 21 February 2018]. Available at: https://www.who.int/ncds/ surveillance/steps/Iran_2011_STEPS_Report.pdf?ua=1

31. Mbouemboue OP, Derew D, Tsougmo JO, Tangyi Tamanji M. A community-based assessment of hypertension and some other cardiovascular disease risk factors in Ngaoundéré, Cameroon. Int J Hypertens 2016; 2016: 4754636.

32. Wang G, Zhou X, Zhuo X, Zhang P. Annual total medical expenditures associated with hypertension by diabetes status in U.S. adults. Am J Prev Med 2017; 53: S182-S189.

33. World Health Organization. Noncommunicable diseases in the Eastern Mediterranean Region. [Update 2010; Accessed 2018 January 27]. Available at: http://apps.who.int/iris/ handle/10665/250371

34. World Health Organization. A global brief on hypertension. Silent killer, global public health crisis. [Update 2013; Accessed 2018 February 25]. Available at: http://apps.who. int/iris/bitstream/handle/10665/79059/WHO_DCO_ WHD_2013.2_eng.pdf?sequence $=1$

35. World Health Organization. Cardiovascular diseases (CVDs) [Update 2017; Accessed 2018 April 1]. Available from: https:// www.who.int/en/news-room/fact-sheets/detail/cardiovasculardiseases-(cvds)

36. Finegold JA, Asaria P, Francis DP. Mortality from ischaemic heart disease by country, region, and age: statistics from World Health Organisation and United Nations. Int J Cardiol 2013; 168: 934-945.
37. World Health Organization. Global atlas on cardiovascular disease prevention and control: Policies, strategies and interventions. [Update 2011; Accessed 2018 May]. Available from: https://www.who.int/cardiovascular_diseases/ publications/atlas_cvd/en/

38. Al-Asadi JN, Habib HA. Risk factors and 30-day case fatality of first-ever stroke in Basrah, Iraq. Niger Med J2014; 55: 209-213.

39. IHME. Iraq. [Update 2018; Accessed 2018 April 1]. Available from: http://www.healthdata.org/iraq

40. World Health Organization. Iraq Family health survey 2006/07 [Update 2008; Accessed 2018 May 5]. Available from: https:// www.who.int/mediacentre/news/releases/2008/pr02/2008_ iraq_family_health_survey_report.pdf

41. Fazlollahi MR, Najmi M, Fallahnezhad M, Sabetkish N, Kazemnejad A, Bidad K, et al. The prevalence of asthma in Iranian adults: The first national survey and the most recent updates. Clin Respir J 2018; 12: 1872-1881.

42. GBD 2016 Disease and Injury Incidence and Prevalence Collaborators. Global, regional, and national incidence, prevalence, and years lived with disability for 328 diseases and injuries for 195 countries, 1990-2016: a systematic analysis for the Global Burden of Disease Study 2016. Lancet 2017; 390: 1211-1259.

43. WHO. Asthma. [Update 2017; Accessed 2018 April 19]. Available from: https://www.who.int/en/news-room/ fact-sheets/detail/asthma

44. Hashem S, Al-Kattan M, Ibrahim SY, Shalaby NM, Shamloul RM, Farrag M. Epilepsy prevalence in Al-Manial Island, Egypt. A door-to-door survey. Epilepsy Res 2015; 117: 133-137. 